\title{
Specialized inpatient treatment of adult anorexia nervosa: effectiveness and clinical significance of changes
}

\author{
Sandra Schlegl ${ }^{1 *}$, Norbert Quadflieg ${ }^{1}$, Bernd Löwe ${ }^{2,3}$, Ulrich Cuntz $^{4,5}$ and Ulrich Voderholzer ${ }^{4,6}$
}

\begin{abstract}
Background: Previous studies have predominantly evaluated the effectiveness of inpatient treatment for anorexia nervosa at the group level. The aim of this study was to evaluate treatment outcomes at an individual level based on the clinical significance of improvement. Patients' treatment outcomes were classified into four groups: deteriorated, unchanged, reliably improved and clinically significantly improved. Furthermore, the study set out to explore predictors of clinically significant changes in eating disorder psychopathology.

Methods: A total of 435 inpatients were assessed at admission and at discharge on the following measures: body-mass-index, eating disorder symptoms, general psychopathology, depression and motivation for change.

Results: $20.0-32.0 \%$ of patients showed reliable changes and 34.1-55.3\% showed clinically significant changes in the various outcome measures. Between $23.0 \%$ and $34.5 \%$ remained unchanged and between $1.7 \%$ and $3.0 \%$ deteriorated. Motivation for change and depressive symptoms were identified as positive predictors of clinically significant changes in eating disorder psychopathology, whereas body dissatisfaction, impulse regulation, social insecurity and education were negative predictors.

Conclusions: Despite high rates of reliable and clinically significant changes following intensive inpatient treatment, about one third of anorexia nervosa patients showed no significant response to treatment. Future studies should focus on the identification of non-responders as well as on the development of treatment strategies for these patients.
\end{abstract}

Keywords: Anorexia nervosa, Cognitive behavioural therapy, Inpatient, Effectiveness, Clinical significance

\section{Background}

Anorexia nervosa is characterized by a pronounced selfinduced weight loss or insufficient weight gain during the period of growth and is associated with an irrational fear of gaining weight as well as a conspicuous distortion of body image. This disorder is relatively common among young women. While the overall incidence rate has remained stable over the past decades, there has been an increased incidence in 15-19 year old girls, a group at elevated risk [1]. The disorder is often characterized by a chronic course and elevated mortality rates $[2,3]$ and thus is one of the diseases with the worst

\footnotetext{
* Correspondence: sandra.schlegl@med.uni-muenchen.de

'Department of Psychiatry and Psychotherapy, University Hospital of Munich (LMU), Munich, Germany

Full list of author information is available at the end of the article
}

prognosis in psychiatry and psychosomatic medicine. Recent state of the art studies suggest that treatment of anorexia nervosa in various settings (outpatient, inpatient, day clinic) is effective [4-6]. In a large randomised controlled trial investigating the efficacy of outpatient treatment of anorexia nervosa significant weight gain as well as reduction in general and eating disorder-specific psychopathology was found [4]. For severe cases of anorexia nervosa with high medical and/or psychosocial risk and a lack of response to less intensive treatments, existing practice guidelines advise inpatient treatment [7-9].

So far, statistical group comparisons have predominantly served to evaluate the effectiveness of inpatient treatment for anorexia nervosa [10-13]. This approach guarantees that the differences found are not based on chance. Yet, it does not provide any information about 
the variability of response rates within a sample. In addition, statistical significance does not enable conclusions to be drawn about whether or not a change in symptoms is clinically relevant [14]. Effect sizes (ES) are better suited to evaluate therapeutic effects because they provide information about the size of a change and are independent of sample size. However, this measure is also relatively independent of the clinical relevance of results [14]. Authors such as Long et al. [15], Rø et al. [16], Tagay et al. [17], Zeeck et al. [18] and Goddard et al. [19] reported small to high effect sizes of inpatient treatment for anorexia nervosa depending on the outcome measure.

To overcome the shortcomings of measuring treatment outcome in terms of statistical significance or effect sizes, Jacobson and colleagues [14,20] developed a concept that considers the clinical relevance of treatment change on an individual basis.

To our knowledge, there is only one study that reports clinically significant changes in inpatients with eating disorders based on the criteria of Jacobson and Truax [14]. Calugi and colleagues [21] found that after treatment $36.4 \%$ of patients with longstanding eating disorder ( $\geq 10$ years) showed clinically significant changes in the Global score of the Eating Disorder Examination (EDE [22]) compared to $44.0 \%$ of those with shorter disease duration. The rest of the patients remained unchanged, no patient deteriorated.

Building on this previous literature, the aim of the current study was to evaluate the outcome of inpatient treatment for anorexia nervosa on an individual basis using the criteria of clinical significance. We used a relativly wide range of outcome measures (body-mass-index (BMI), eating disorder symptoms, general psychopathology and depression). Furthermore, we intended to explore predictors of clinically significant changes in eating disorder psychopathology.

\section{Methods}

\section{Participants}

We investigated a sample of female inpatients who were hospitalised at the Schoen Klinik Roseneck in Prien, Germany between January 2009 and January 2014. Inclusion criteria were a diagnosis of anorexia nervosa according to ICD-10 (F50.00, F50.01) including intense fear of gaining weight, a distorted body image and a BMI less than or equal to 17.5. Patients were diagnosed by experienced clinicians from the highly specialized eating disorder unit (all with a minimum master's degree in medicine or psychology) during a standard intake interview. Furthermore, a minimum age of 18 years was mandatory. Exclusion criteria were drug/alcohol/medication abuse, acute suicidal tendencies, psychotic symptoms or a severe life-threatening somatic disorder.
Patients were 'regularly' discharged if they achieved the target weight $(\mathrm{BMI}>18$ in accordance with eating disorder guidelines [9]). Patients who did not achieve the target weight (mostly those with a very low BMI at admission) were 'regularly' discharged if follow-up treatment was assured (e.g. a re-admission was planned). Patients were 'prematurely' discharged if they had insufficient therapy motivation or for disciplinary reasons.

All participants gave written and signed informed consent. The study was approved by the responsible Medical Ethics Committee of the University of Munich.

\section{Inpatient treatment program}

All patients received a multimodal inpatient treatment program based on cognitive-behavioural therapy with group and individual psychotherapy. The manualised eating disorder-specific group therapy consisted of nine therapy sessions, each lasting 100 minutes. The main elements were psycho-education, behavioural and functional analysis, acceptance of one's own body, dealing with emotions and needs, and relapse prevention. The general group psychotherapy took place up to three times a week and each session lasted 90 to 100 minutes. Patients received individual therapy once or twice a week for one hour. Additional therapy elements included social skills training, art therapy, attending classes in the teaching kitchen and exercise therapy. Patients were required to gain $700 \mathrm{~g}$ of body weight per week. Cotherapists weighed the patients twice a week in the morning and weight gain was visualised on charts. If patients with anorexia nervosa failed to gain weight, further steps were taken: increase of food intake and monitoring during meal times, administration of high caloric fluids or feeding through a nasal tube.

\section{Measures}

A standard set of self-rating questionnaires were used to assess eating disorder symptomatology, general psychopathology and depression at admission and discharge.

The Eating Disorder Inventory-2 (EDI-2) [23,24] was used for the multidimensional assessment of the specific psychopathology of patients with eating disorders. It consists of 11 scales with 91 items that can be answered on a six-point scale from 1 (never) to 6 (always). Cronbach's Alpha for the EDI-2 Global score for this sample was .96 at admission. Cronbach's Alphas for the subscales are given in online supplemental materials (see Additional file 1).

The Brief Symptom Inventory (BSI) [25,26] assesses current general psychological distress of patients throughout the last week on the basis of 53 items belonging to nine subscales. Answers are given on a five-point scale, ranging from 0 (not at all) to 4 (extremely). Three global parameters can be calculated. In the present 
study, the global severity index (GSI) was used. Cronbach's Alpha for the GSI for this sample was .96.

The Beck Depression Inventory-2 (BDI-2) $[27,28]$ is a self-rating instrument to assess the severity of depressive symptoms. Patients can rate each item on a fourpoint scale from 0 to 3 in terms of its occurrence and its intensity during the last seven days. The cut-off for clinically relevant depressive symptoms is 20. Cronbach's Alpha for the BDI-2 was .92.

Higher scores in these three instruments indicate greater psychopathology.

The treating therapist rated the patient's motivation for changing their eating disorder behaviours at admission on a scale from 0 (not at all motivated) to 4 (highly motivated).

Additionally, sociodemographic and clinical characteristics (e.g. BMI ad admission and at discharge, duration of inpatient treatment, duration of the eating disorder, comorbidity) were available from each patient's clinical records.

\section{Statistical analysis}

In order to examine the effectiveness of inpatient treatment for anorexia nervosa, results were analysed in three different ways:

- Statistical group comparisons (repeated measures analyses of variance (rANOVAs) with treatment duration as covariate).

- Calculation of effect sizes.

- Assessment of treatment outcome on the basis of individual changes according to the criteria of clinical significance [14].

Effect sizes were calculated using the formula $\left(\mathrm{M}_{\text {pre }}{ }^{-}\right.$ $\left.\mathrm{M}_{\text {post }}\right) / \mathrm{SD}_{\text {pre }}$. Interpretation of the effect size was corrected by the effects of an untreated control group, i.e. $\mathrm{ES}=0.10$, as proposed for single group pre-post study designs by Grawe et al. [29]. Therefore, an ES $>0.30$ is considered a small effect, an ES $>0.60$ a medium effect and an ES $>0.90$ a large effect.

\section{The concept of clinical significance}

The concept of clinical significance by Jacobson and colleagues $[14,20]$ is a construct used to evaluate clinically meaningful changes resulting from therapy. It consists of a two-part criterion: To qualify as clinically significantly improved after treatment, a patient has to i) show a reliable change, i.e. statistically significant improvement and ii) cross the cut-off point for a clinically significant change.

\section{The criterion of statistical significance/reliable change}

To classify a patient as having shown a statistically significant change (i.e. that the observed change is not based on errors of measurement or chance), an individual minimal pre-post change (from admission to discharge) is necessary.

Therefore, the reliable-change-index (RCI) has to be exceeded, and this is calculated as follows: $R C I=\frac{\mathrm{X}_{\text {pre }}-\mathrm{X}_{\text {post }}}{\mathrm{S}_{\mathrm{diff}}}>$ 1.96 with $S_{\text {diff }}=\sqrt{2(\mathrm{SE})^{2}}$ and $\mathrm{SE}=\mathrm{s}_{1} \sqrt{\left(1-\mathrm{r}_{\mathrm{xx}}\right)}$.

Here $X_{\text {pre }}$ represents the pre-test score and $X_{\text {post }}$ the post-test score of a patient. Additionally, the standard error of measurement (SE), the standard deviation of the patient group at pretest $\left(\mathrm{s}_{1}\right)$ and a measure for the reliability of the measurement ( $\mathrm{r}_{\mathrm{xx}}=$ Cronbach's $\alpha$ ) are included in this formula. $S_{\text {diff }}$ stands for the standard error of difference between the two test scores.

\section{The criterion of clinical significance}

A reliable change is considered to be a precondition for a clinically relevant change. As a second step, a cut-off is defined in order to assess whether a patient should be assigned to the healthy or clinical group after treatment.

For the present study, cut-off point $\mathrm{C}$ according to the classification by Jacobson and Truax [14] was used. This cut-off is a weighted midpoint between the means of a functional and a dysfunctional population [30]: $C=\frac{S D_{0} * M_{1}+S D_{1} * M_{0}}{S D_{0}+S D_{1}} \cdot \mathrm{M}_{0}$ and $\mathrm{SD}_{0}$ represent the mean and standard deviation of the normative sample, $\mathrm{M}_{1}$ and $\mathrm{SD}_{1}$ the mean and standard deviation of the patient group at pre-test. Norms for the healthy samples were taken from the applicable manuals $[24,26,28]$. Reaching the cutoff means that, following treatment, a patient is closer to the mean of a functional population than to the mean of inpatients with anorexia nervosa at admission.

According to the cut-off, patients can be classified into five treatment outcome groups:

1. Normative: patients with normative scores both at admission and discharge.

2. Deteriorated: statistically significant worsening $(\mathrm{RCI} \leq-1.96)$ of patients; clinical significance is not of interest as the result is clearly unwanted.

3. Unchanged: patients with scores above norm at admission and statistically non-significant individual changes at discharge.

4. Reliably improved: statistically significant improvement $(\mathrm{RCI} \geq 1.96)$ of patients between pre- and post-measurement.

5. Clinically significantly improved: patients with statistically significant improvement and symptoms within the normal range of a functional sample at the end of therapy.

In this study, only patients from groups 2 through 5 were considered in the analyses of each separate scale. 
We did not include patients with normative scores since improvement was not an issue.

To investigate differences between the different treatment outcome groups, ANOVAs or Chi-Square-Tests with post-hoc tests were calculated.

A stepwise binary logistic regression was calculated using the backward likelihood ratio method to identify predictors of clinically significant changes in the EDI-2 Global score. We divided patients into two groups: those who showed clinically significant change and those who did not (i.e. we grouped together patients who showed reliable change, patients who were unchanged, and patients who had deteriorated). We first tested for differences between these two groups in terms of sociodemographic variables, clinical characteristics and baseline subscales. In a second step, we included these variables as predictors in the regression analyses, if they showed significant differences between the patient groups and if they showed no multi-collinearity.

All statistical analyses were performed with SPSS version 22.0. The Bonferroni correction was used for multiple-comparison correction. Based on running $15 \mathrm{~F}-$ tests alpha was set at .003. To reflect actual clinical practice, patients who were discharged regularly, as well as those who were discharged prematurely, were included in analyses, with no replacement of missing values.

\section{Results}

\section{Study sample}

As shown in the participant flow chart (Figure 1) between January 2009 and January 2014748 adult female patients with anorexia nervosa (F50.00/F50.01) were treated as inpatients in the Schoen Klinik Roseneck. Due to administrative regulations, EDI-2 data were not available from $n=313$ patients. There were no significant differences between those for whom EDI-2 data were available and those for whom data were unavailable in terms of BMI at admission, age, treatment duration, duration of illness, previous inpatient and outpatient treatments. Furthermore, there were no differences in BMI change during inpatient treatment between these two groups. A total of 435 inpatients with anorexia nervosa were included in the analyses of whom $n=294$ regularly completed treatment and $n=141$ were premature discharges (see Table 1 for more detail). Patients had a mean age of $\mathrm{M}=26.36(\mathrm{SD}=9.02)$. BMI at admission was $14.56 \mathrm{~kg} / \mathrm{m}^{2}$ ( $\left.\mathrm{SD}=1.74\right)$. Individual length of admission varied considerably (6-260 days) and mean duration

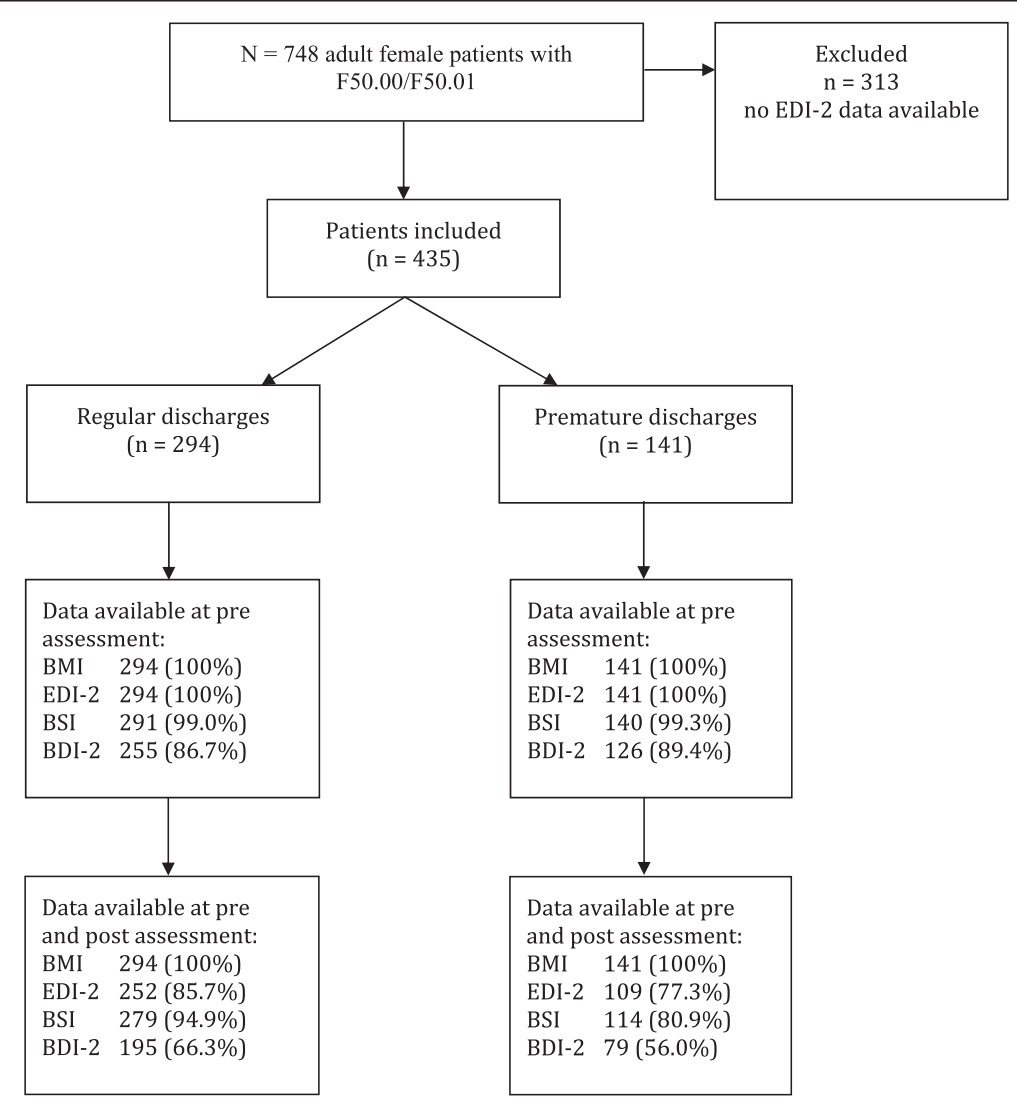

Figure 1 Flow chart of patient sample. Notes: $\mathrm{BMI}=$ Body-mass-index, $\mathrm{EDI}-2=$ Eating disorder inventory-2, BSI = Brief symptom inventory, $\mathrm{BDI}-2=$ Beck depression inventory -2 . 
Table 1 Sociodemographic and clinical characteristics of anorexia nervosa inpatients $(N=435)$ at admission

\begin{tabular}{|c|c|c|}
\hline Variables & $\mathrm{M}(\mathrm{SD})$ & Range \\
\hline Age (years) & $26.36(9.02)$ & $18-70$ \\
\hline Inpatient treatment duration (days) & $91.79(44.26)$ & $6-260$ \\
\hline Body-Mass-Index $\left(\mathrm{kg} / \mathrm{m}^{2}\right)$ & $14.56(1.74)$ & $9.69-17.48$ \\
\hline Duration of the eating disorder (years) & $8.84(7.81)$ & $1-50$ \\
\hline Number of previous inpatient treatment & $1.86(2.45)$ & $0-15$ \\
\hline Number of previous outpatient treatment & $1.73(1.57)$ & $0-9$ \\
\hline Variables & n (\%) & \\
\hline \multicolumn{3}{|l|}{ Type of discharge } \\
\hline Regular & $292(67.1)$ & \\
\hline Premature & $139(32.0)$ & \\
\hline Prematurely discontinued by the patient & $32(7.4)$ & \\
\hline $\begin{array}{l}\text { Prematurely discharged by } \\
\text { mutual agreement }\end{array}$ & $94(21.6)$ & \\
\hline Insufficent insurance coverage & $1(0.2)$ & \\
\hline Transfer & $12(2.8)$ & \\
\hline \multicolumn{3}{|l|}{ Subtype of anorexia nervosa } \\
\hline F 50.00 (Restricting Type) & $316(72.6)$ & \\
\hline F 50.01 (Binge Eating/Purging Type) & $111(25.5)$ & \\
\hline \multicolumn{3}{|l|}{ Comorbidity $^{1}$} \\
\hline Moderate depressive episode (F32.1) & $117(26.9)$ & \\
\hline Severe depressive disorder ${ }^{2}$ (F32.2) & $28(6.4)$ & \\
\hline $\begin{array}{l}\text { Recurrent moderate depressive } \\
\text { disorder (F33.1) }\end{array}$ & $89(20.5)$ & \\
\hline Recurrent severe depressive disorder ${ }^{2}$ (F33.2) & $42(9.7)$ & \\
\hline Social phobia (F40.1) & $39(9.0)$ & \\
\hline Predominantly compulsive acts (F42.1) & $24(5.5)$ & \\
\hline Posttraumatic stress disorder (F43.1) & $32(7.4)$ & \\
\hline $\begin{array}{l}\text { Emotionally unstable personality } \\
\text { disorder (F60.3) }\end{array}$ & $34(7.8)$ & \\
\hline
\end{tabular}

Notes: ${ }^{1}$ Only diagnoses pertaining to more than $5 \%$ of included patients are indicated, ${ }^{2}$ without psychotic symptoms.

of inpatient treatment was 91.79 days $(\mathrm{SD}=44.26)$. The sociodemographic and clinical characteristics of the sample are presented in Table 1. For participants who were discharged prematurely, there were no differences in sociodemographic and clinical variables between those with available EDI-2 discharge data and those without. However, differences emerged for the patients who were discharged regularly: those with no discharge data had a lower BMI at admission, more depressive symptoms, more general psychopathology, and more previous inpatient treatments than those with discharge data.

\section{Body weight and eating disorder symptomatology}

BMI rose on average from $14.56 \mathrm{~kg} / \mathrm{m}^{2}$ ( $\mathrm{SD}=1.74$ ) to $17.18 \mathrm{~kg} / \mathrm{m}^{2}(\mathrm{SD}=1.86)(\mathrm{ES}=1.51)$ during inpatient treatment. Treatment duration significantly contributed to pre-post change in body weight. The total mean weight increase was $7.33 \mathrm{~kg}(\mathrm{SD}=4.31)$. The mean weight increase per week was $0.84 \mathrm{~kg}(\mathrm{SD}=0.56) .52 .2 \%$ of the patients remained in the anorectic BMI range ( $\leq$ $17.5)$ at discharge. Of 435 patients 108 (24.8\%) reached a BMI $\geq 18.5$ at discharge. For patients who were discharged regularly, percentages were $38.3 \%$ (BMI $\leq 17.5$ ) and $33.1 \%$ (BMI $\geq 18.5)$.

As shown in Table 2, all scales of the EDI-2 indicated statistically significant changes after treatment. The largest effect sizes were found for Drive for Thinness, the EDI-2 Global score and Interoceptive Awareness, whereas the lowest were achieved for Body Dissatisfaction, Interpersonal Distrust and Perfectionism. Treatment duration only had a significant effect on pre-post change in $I n$ teroceptive Awareness.

Additional file 1 shows mean and standard deviations of community norms, the patients' pre-treatment scores and the reliabilities used to calculate cut-offs for a clinically significant change. Furthermore, numbers of patients in the normative range for each scale are given in Additional file 1.

Results show that $27.7 \%$ of the patients improved reliably on the Global score of the EDI-2. 35.6\% fulfilled the criteria for a clinically significant change. In contrast, $34.5 \%$ remained unchanged and $2.2 \%$ showed worsened symptoms (see Figure 2). Additional file 2 presents the classification of treatment outcome based on the criteria of Jacobson and Truax [14] for all subscales of the EDI-2.

\section{General psychopathology}

Change on the GSI of the BSI was statistically significant. Treatment duration had a significant effect on pre-post change in regard to GSI. The effect size was medium (ES = 0.82) (see Table 2). $32.0 \%$ of the patients showed reliable changes during inpatient treatment according to the GSI, $34.1 \%$ were clinically significantly improved, $30.8 \%$ unchanged and 3.0\% worse (see Figure 2).

\section{Depression}

Depressive symptoms significantly improved after treatment with a large effect size of ES $=1.26$ (see Table 2). Regarding the BDI-2, the distribution of treatment outcome groups was as follows: $20.0 \%$ of patients were reliably improved, $55.3 \%$ were clinically significantly improved and $23.0 \%$ remained unchanged. $1.7 \%$ of the patients deteriorated (see Figure 2).

\section{Differences between deteriorated/unchanged, reliably improved and clinically significantly improved patients in regard to baseline variables}

Since the number of deteriorated patients was very low, these were combined with the unchanged patients. Table 3 shows that clinically significantly improved patients had 
Table 2 Pre-post results regarding BMI, EDI-2, BSI and BDI-2

\begin{tabular}{|c|c|c|c|c|c|c|c|}
\hline & \multirow{3}{*}{$\begin{array}{l}\text { Pretreatment } \\
M(S D)\end{array}$} & \multirow{3}{*}{$\begin{array}{l}\text { Posttreatment } \\
M(S D)\end{array}$} & \multicolumn{4}{|l|}{ rANOVAs } & \multirow[t]{3}{*}{ ES } \\
\hline & & & \multicolumn{2}{|c|}{ Pre-post change } & \multicolumn{2}{|c|}{$\begin{array}{l}\text { Interaction between treatment } \\
\text { duration and pre-post change }\end{array}$} & \\
\hline & & & $F(d f)$ & $\mathrm{p}$ & $F(d f)$ & $p$ & \\
\hline$\overline{B M I}$ & $14.56(1.74)$ & $17.18(1.86)$ & $24.77(1)$ & $<.001$ & $256.04(1)$ & $<.001$ & 1.51 \\
\hline \multicolumn{8}{|l|}{ EDI-2 } \\
\hline Drive for Thinness & $29.38(8.80)$ & $21.69(8.69)$ & $47.96(1)$ & $<.001$ & $3.15(1)$ & .077 & 0.87 \\
\hline Bulimia & $16.95(9.38)$ & $10.62(5.03)$ & $25.50(1)$ & $<.001$ & $1.97(1)$ & .162 & 0.67 \\
\hline Body dissatisfaction & $38.24(9.39)$ & 33.85 (10.49) & $24.53(1)$ & $<.001$ & $0.44(1)$ & .510 & 0.47 \\
\hline Ineffectiveness & $36.93(10.38)$ & $30.10(10.60)$ & $34.03(1)$ & $<.001$ & $1.57(1)$ & .211 & 0.66 \\
\hline Perfectionism & $22.90(6.20)$ & $20.97(5.98)$ & $8.09(1)$ & .005 & $0.48(1)$ & .487 & 0.31 \\
\hline Interpersonal distrust & $23.77(6.69)$ & $21.11(6.65)$ & $9.18(1)$ & .003 & $2.89(1)$ & .090 & 0.40 \\
\hline Interoceptive awareness & $35.91(9.52)$ & $28.90(9.42)$ & $24.33(1)$ & $<.001$ & $5.50(1)$ & .020 & 0.74 \\
\hline Maturity fears & $27.72(7.90)$ & $24.03(7.43)$ & $9.72(1)$ & .002 & $3.33(1)$ & .069 & 0.47 \\
\hline Asceticism & $25.97(7.49)$ & $21.84(7.26)$ & $14.75(1)$ & $<.001$ & $2.33(1)$ & .128 & 0.55 \\
\hline Impulse regulation & $28.36(7.62)$ & $24.29(7.89)$ & $19.62(1)$ & $<.001$ & $0.63(1)$ & .428 & 0.53 \\
\hline Social insecurity & $28.27(6.63)$ & $24.84(7.10)$ & $19.37(1)$ & $<.001$ & $0.85(1)$ & .356 & 0.52 \\
\hline EDI-2 Global score & 313.69 (62.85) & $262.00(66.42)$ & $42.95(1)$ & $<.001$ & $3.79(1)$ & .052 & 0.82 \\
\hline BSI GSI & $1.33(0.70)$ & $0.76(0.57)$ & $32.19(1)$ & $<.001$ & $11.17(1)$ & .001 & 0.82 \\
\hline BDI-2 & $28.53(11.60)$ & $13.97(11.24)$ & $52.49(1)$ & $<.001$ & $3.06(1)$ & .082 & 1.26 \\
\hline
\end{tabular}

Notes: $\mathrm{BMI}=$ Body-mass-index, EDI-2 = Eating disorder inventory-2, BSI = Brief symptom inventory, GSI = Global severity index, $\mathrm{BDI}-2=$ Beck depression inventory-2, $E S=$ effect size, treatment duration as covariate.

fewer symptoms of both general and eating disorder psychopathology at admission, and a lower rate of comorbid recurrent severe depression and of posttraumatic stress disorder. They were more motivated for treatment and had a higher rate of moderate depression. Deteriorated/ unchanged patients showed a higher rate of comorbid recurrent severe depression and posttraumatic stress disorder.
Predictors for a clinically significant change in the Global score of the EDI-2

A higher motivation for change as well as more depressive symptoms turned out to be significant predictors for a clinically significant change whereas body dissatisfaction, impulse regulation, social insecurity and education were negative predictors (see Table 4). These factors explained $35.0 \%$ of the variance in scores (Nagelkerke's $\mathrm{R}^{2}$ ).

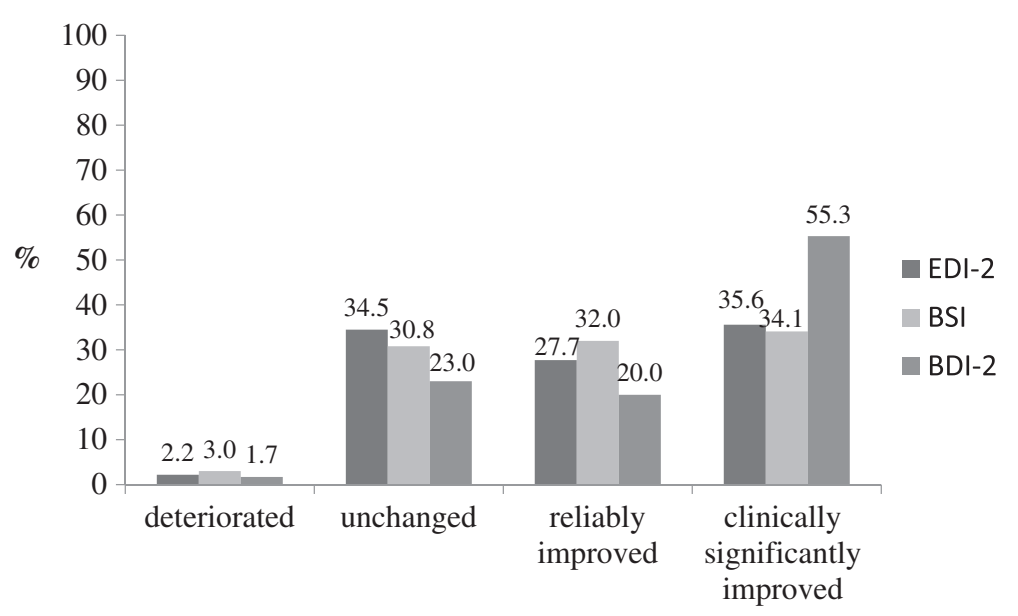

Figure 2 Treatment outcome on the Global scores using the criteria of clinical significance. Notes: EDI-2 = Eating disorder inventory-2, $\mathrm{BSI}=$ Brief symptom inventory, $\mathrm{BDI}-2=$ Beck depression inventory-2. 
Table 3 Differences between outcome groups on the EDI-2 global score

\begin{tabular}{|c|c|c|c|c|c|}
\hline & $\begin{array}{l}\text { Deteriorated/ } \\
\text { unchanged (G1) }\end{array}$ & $\begin{array}{l}\text { Reliably } \\
\text { improved (G2) }\end{array}$ & $\begin{array}{l}\text { Clinically significantly } \\
\text { improved (G3) }\end{array}$ & & \\
\hline & $M(S D)$ & $M(S D)$ & $M(S D)$ & ANOVA & Post-hoc \\
\hline Age (years) & $25.35(8.87)$ & $25.94(8.40)$ & $26.19(7.79)$ & $F(2,168)=0.16, p=.853$ & $\mathrm{G} 1=\mathrm{G} 2=\mathrm{G} 3$ \\
\hline Inpatient treatment duration (days) & $88.56(42.01)$ & $103.41(37.82)$ & 86.37 (34.78) & $F(2,168)=3.03, p=.051$ & $\mathrm{G} 3=\mathrm{G} 1=\mathrm{G} 2$ \\
\hline Body-Mass-Index $\left(\mathrm{kg} / \mathrm{m}^{2}\right)$ at admission & $14.65(1.54)$ & $14.75(1.80)$ & $14.95(2.02)$ & $F(2,168)=0.44, p=.645$ & $\mathrm{G} 1=\mathrm{G} 2=\mathrm{G} 3$ \\
\hline Duration of the eating disorder (years) & $8.27(6.77)$ & 8.65 (8.09) & $8.50(6.78)$ & $F(2,168)=0.04, p=.958$ & $\mathrm{G} 1=\mathrm{G} 3=\mathrm{G} 2$ \\
\hline Number of previous inpatient treatment & $1.96(1.64)$ & $1.75(1.47)$ & $1.73(1.33)$ & $F(2,168)=0.43, p=.649$ & $\mathrm{G} 3=\mathrm{G} 2=\mathrm{G} 1$ \\
\hline Number of previous outpatient treatment & $2.32(2.88)$ & $2.10(2.34)$ & $1.29(1.54)$ & $F(2,168)=2.96, p=.055$ & $\mathrm{G} 3=\mathrm{G} 2=\mathrm{G} 3$ \\
\hline Motivation & $2.09(1.11)$ & $2.43(1.17)$ & $2.54(1.07)$ & $F(2,213)=3.45, p=.034$ & $\mathrm{G} 2=\mathrm{G} 1<\mathrm{G} 3$ \\
\hline BDI-2 at baseline & $30.34(10.83)$ & $37.51(9.11)$ & $27.21(10.07)$ & $F(2,168)=14.13, p<.001$ & $\mathrm{G} 3=\mathrm{G} 1<\mathrm{G} 2$ \\
\hline BSI at baseline & $1.56(0.66)$ & $1.87(0.51)$ & $1.24(0.59)$ & $F(2,168)=14.01, p<.001$ & $\mathrm{G} 3<\mathrm{G} 1<\mathrm{G} 2$ \\
\hline \multirow[t]{2}{*}{ EDI-2 Global score at baseline } & $333.59(46.52)$ & $373.10(32.55)$ & $305.77(33.60)$ & $F(2,168)=38.78, p<.001$ & $\mathrm{G} 3<\mathrm{G} 1<\mathrm{G} 2$ \\
\hline & n (\%) & n (\%) & n (\%) & $\mathrm{x}^{2}$-Test & Post-hoc \\
\hline \multicolumn{6}{|l|}{ Comorbidity } \\
\hline \multirow[t]{3}{*}{ Moderate depressive episode (F32.1) } & $33(32.4)$ & $18(23.4)$ & $41(41.4)$ & $x^{2}(2,278)=6.40, p=.041$ & $\mathrm{G} 2<\mathrm{G} 3$ \\
\hline & & & & & $\mathrm{G} 1=\mathrm{G} 3$ \\
\hline & & & & & $\mathrm{G} 2=\mathrm{G} 1$ \\
\hline \multirow{2}{*}{$\begin{array}{l}\text { Recurrent severe depressive } \\
\text { disorder }^{1} \text { (F33.2) }\end{array}$} & $12(11.8)$ & $15(19.5)$ & $4(4.0)$ & $x^{2}(2,278)=10.48, p=.005$ & $\mathrm{G} 3<\mathrm{G} 2=\mathrm{G} 1$ \\
\hline & & & & & $\mathrm{G} 3=\mathrm{G} 2$ \\
\hline \multirow[t]{3}{*}{ Posttraumatic stress disorder (F43.1) } & $13(12.8)$ & $6(7.8)$ & $2(2.0)$ & $x^{2}(2,278)=8.28, p=.016$ & $\mathrm{G} 3<\mathrm{G} 1$ \\
\hline & & & & & $\mathrm{G} 2=\mathrm{G} 1$ \\
\hline & & & & Kruskal-Wallis-Test & Post-hoc \\
\hline \multicolumn{6}{|l|}{ Education } \\
\hline Still in school & $4(3.9)$ & $3(3.9)$ & $9(9.1)$ & $H(2)=7.34, p=.026$ & $\mathrm{G} 3=\mathrm{G} 1$ \\
\hline No graduation & $1(1.0)$ & - & - & & $\mathrm{G} 1=\mathrm{G} 2$ \\
\hline Secondary general school certificate & $7(6.9)$ & $4(5.2)$ & $7(7.1)$ & & $\mathrm{G} 3<\mathrm{G} 2$ \\
\hline Intermediate school certificate & $25(24.5)$ & $13(16.9)$ & $30(30.3)$ & & \\
\hline Higher education entrance qualification & $64(62.7)$ & $56(72.7)$ & $53(53.5)$ & & \\
\hline
\end{tabular}

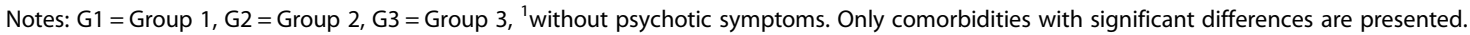

\section{Discussion}

The aim of this study was to evaluate the effectiveness of inpatient treatment for anorexia nervosa according to the criteria of clinical significance of Jacobson and colleagues $[14,20]$. This construct allowed detailed analyses

\section{Table 4 Predictors of a clinically significant change of} EDI-2 global score

\begin{tabular}{llllll}
\hline & $\boldsymbol{B}$ & S.E. & Wald & $\mathbf{p}$ & OR (95\% Cl) \\
\hline EDI-2 Body dissatisfaction & -.070 & .02 & 9.38 & .002 & $0.93(0.89-0.98)$ \\
EDI-2 Impulse regulation & -.066 & .03 & 4.26 & .039 & $0.94(0.88-1.00)$ \\
EDI-2 Social insecurity & -.088 & .04 & 5.23 & .022 & $0.92(0.85-0.99)$ \\
Moderate depressive & 1.049 & .39 & 7.21 & .007 & $2.85(1.33-6.13)$ \\
episode (F32.1) & & & & & \\
Education & -.475 & .20 & 5.69 & .017 & $0.62(0.42-0.92)$ \\
Motivation for change & .401 & .18 & 5.19 & .023 & $1.49(1.06-2.11)$ \\
\hline
\end{tabular}

Note: EDI-2 = Eating disorder inventory-2. of treatment outcome on an individual basis. The results showed that - depending on the outcome measure one-third to more than one half of the patients showed clinically significant changes. Furthermore, the rate of patients with reliable changes was more than $30 \%$.

Lambert and Ogles [31] assume that $25-30 \%$ of patients generally do not change during psychotherapy and that about $5-10 \%$ even worsen during treatment. Our non-response rates are somewhat higher than the ones reported by these authors, while deterioration rates are somewhat lower.

Our rate of clinically significant improvement following inpatient treatment for anorexia nervosa is comparable to the findings of Calugi and colleagues [21], whereas the non-response rate found in our sample was only half of that in the comparison study. In contrast to our study, which used the self-rated EDI-2 Global score to evaluate treatment outcome, Calugi and colleagues [21] used the 
EDE semi-structured interview. Therefore, our self-rating instrument might have overestimated effects compared to the expert rating.

The high effect size of ES $=1.51$ for the BMI is larger than a meta-analytically calculated effect size of inpatient treatment for anorexia nervosa with $\mathrm{ES}=1.19$ (CI: 1.07 1.30) [32]. However, despite the considerable weight gain, $52.2 \%$ of patients remained in the anorectic BMI range at discharge. This result is comparable with Goddard and colleagues [19] who also found that more than half of their patients did not reach a BMI $>17.5$ during inpatient treatment. One explanation is the severity of anorexia nervosa in inpatient samples. In our sample individuals suffered from long-term anorexia nervosa (mean illness duration of almost 10 years) and had a rather low BMI at admission.

For depression, as measured by the BDI-2, the large effect size is consistent with the finding by Bowers et al. [10]. The medium effect sizes found for the Global scores of EDI-2 and the general psychopathology in this study are in line with effects shown in previous studies examining the effectiveness of inpatient treatment for anorexia nervosa $[12,13,33,34]$.

Treatment duration had a significant effect on BMI change as well as on changes in Interoceptive Awareness and general psychopathology (GSI). Other subscales were not significantly influenced by treatment duration. This is in line with results from Morris et al. [11], who found that length of inpatient stay was significantly correlated with BMI change but not with change in EDE questionnaire. Collin et al. [12] also reported that length of current admission was a predictor of BMI change, but not of EDE change or change in the SCL-90 (Symptom Checklist-90) global severity index [35].

When comparing deteriorated/unchanged, reliably improved and clinically significantly improved patients, differences in regard to numerous baseline variables were found. Clinically significantly improved patients were less severely ill at admission, i.e. they showed less symptoms in terms of general and eating disorder psychopathology at admission and had a lower rate of comorbid disorders (recurrent severe depression, posttraumatic stress disorder). One plausible explanation as to why these patients had the highest rate of clinically significant changes is that lower scores at baseline make it easier to reach the cut-off for a clinically significant change. Clinically significantly improved patients were also more motivated, which may also explain why they showed the most pronounced treatment effects. Comorbid depression was also observed in patients with clinically significant changes. A positive protective effect of depression was also found by Zeeck et al. [36], who reported that inpatients with anorexia nervosa and comorbid depression stayed longer in psychotherapy than those without comorbid depression. These patients therefore have a higher chance for clinically significant changes. Deteriorated/unchanged patients showed a higher rate of severe comorbid conditions (recurrent severe depression, posttraumatic stress disorder).

The regression analysis emphasized the relevance of high internal motivation for change as a predictive factor for a better treatment outcome at the time of discharge. Previous studies have also found that a higher baseline motivation is an important predictor for change in anorexia nervosa inpatients $[37,38]$. These results suggest that motivational strategies should be a key starting point for improving the effectiveness of inpatient treatment for anorexia nervosa. One possible future approach is to increase the patients' readiness for change, for example using Motivational Interviewing techniques [39] which also showed promise for the treatment of patients with eating disorders [40]. Furthermore, body dissatisfaction was identified as a negative predictor of a clinically significant change. This is in line with results from other studies which have found that body dissatisfaction is a negative predictor of weight increase [41,42]. In our study, impulse regulation was a negative predictor of short-term outcome. Fichter et al. [43] also found that impulse regulation was a negative predictor at 12 year follow-up. While Karllson et al. [41] found that social insecurity was a positive predictor for weight gain, we found that it was a negative predictor for clinically significant change. It may be that social insecurity leads to reduced therapeutic alliance and therefore a less favourable treatment outcome. A comorbid moderate depressive episode was found to be a positive predictor of clinically significant change. This contrasts with previous studies which have shown that depressive symptoms are a negative predictor of treatment outcome [43]. Furthermore, Calugi et al. [44] showed that there were no differences in outcome between eating disorder patients with or without a comorbid major depressive disorder. Our results should be interpreted carefully since comorbidity was not assessed by a structured clinical interview such as the Structured Clinical Interview for DSM Disorders [45], but rather based on expert opinion. When comparing values of depressive symptoms among the unchanged, the reliably improved and clinically significantly improved patients in our study, results showed that clinically significantly improved patients had the lowest depressive symptoms. Finally, a higher education was identified as negative predictor for treatment outcome. This contrasts with findings from Huas et al. [46], who found that low educational status was a predictor of dropout from inpatient treatment for anorexia nervosa, which is linked in general to poorer outcomes.

\section{Strengths and limitations}

To the best of our knowledge, this study includes the largest sample size of anorexia nervosa patients treated as inpatients. Furthermore, strength of the study is that 
it also evaluates individual treatment outcomes. This enables a more realistic view of treatment outcomes than comparisons of means and effect sizes do [47]. A further advantage of the study is the naturalistic sample. In comparison to data from randomised controlled trials, data from naturalistic settings may yield more clinically useful findings [48] because they represent the heterogeneous nature of the cases, settings, referral routes, and therapists that characterise everyday clinical practice [49]. These factors enable more valid conclusions to be drawn about treatment improvement.

The strength of the clinical significance concept lies in its applicability to individual cases. Furthermore, evaluation of each individual patient with regard to normative functioning is of great value for clinical practice [30].

There are several limitations. First, the data do not represent all patients with anorexia nervosa admitted in the defined period but rather those for whom baseline and discharge questionnaires were available (about 50\%). There were no differences between those with and without missing baseline data in terms of sociodemographic and clinical variables. Furthermore, there were no differences in BMI change during inpatient treatment. However, there were differences between those with and without discharge questionnaires. Since patients who did not complete discharge assessment were more severely ill, results may have overestimated treatment effects. On the other hand, we included outcome data from patients who were prematurely discharged so that our results may after all give a conservative evaluation of treatment outcome. Analyses of only those patients who were discharged regularly might have revealed more positive outcomes. Second, all data except those for the BMI, were based on self-ratings, and no structured clinical interview was conducted. Diagnoses were finally fixed at the end of treatment, giving the expert rater a broad vision of the patient's behaviour. Third, no follow-up data could be collected to provide data on the long-term outcome of inpatient treatment for anorexia nervosa. Fourth, although one item rated therapy motivation as a predictor of treatment outcome, this has neither been validated against other measures that assess motivation, nor has its reliability been established. One study assessing readiness to change (University of Rhode Island Change Assessment, [50]) in inpatients with anorexia nervosa found that BMI change was not predicted by the stage of change of the patients [51]. A further limitation of the patient's motivation being rated by the therapist is that the rating data may reflect the motivation of the therapist to some extent, and may influence the motivation of the therapist and consequently treatment quality. Fifth, the method of clinical significance has weaknesses. A statistical limitation of this approach is regression to the mean. Patients with higher scores at admission are those most likely to make huge improvements [52]. Also cut-off point $C$ as a cut-off point between normal and dysfunctional distribution can vary considerably among studies as this criterion depends on the symptom severity in the study sample at baseline. Furthermore, the use of the two criteria to evaluate clinically significant change represents a more stringent measure than most of the previously used criteria. Moreover, one needs to take into account that treatment is, in most cases, not completed when inpatient care concludes. In most cases, inpatient psychotherapy represents a specific phase of a long-term treatment process. Consequently, additional outpatient therapy is required to ensure further improvements of symptoms and a long-term stabilization of achieved effects. There is one caveat, however: patients with anorexia nervosa are often chronically ill and becoming completely symptom-free might be unrealistic, even in the long run.

The paradigm of 'clinically relevant treatment effects' is worthy of some discussion in general. Self-ratings that focus on the assessment of symptoms are certainly important in this context, but it is still only one aspect that must be complemented by other perspectives (e.g. expert ratings). Other factors may equally well indicate clinically relevant treatment effects (e.g. acceptance of disease, improved quality of life, increased knowledge and capability to deal with one's own illness, provision of a basis for improvement of symptoms in the ensuing outpatient therapy).

Although inpatient treatment for anorexia nervosa is effective, a certain percentage of patients do not benefit from it - at least in certain symptom areas. There are several reasons for the absence of significant or clinically relevant treatment effects. For example, a lack of motivation may reduce response to treatment. Additionally, a lack in quality of the therapy (e.g. a poor therapeutic relationship, overestimation of the patient's capabilities) may contribute to non-response. Moreover, adverse external events that occur during inpatient treatment such as relationship breakups, job loss, emerging conflicts, may result in non-response or even a deterioration of symptoms in some patients.

Finally, there is the question of how the concept of clinical significance can be integrated in other definitions of treatment outcome. In outcome research there are many different terms used to describe treatment outcome, e.g. response, (partial) remission, recovery and relapse that are often differently defined [53]. In eating disorders research there are also a variety of definitions of outcome success that are used [54-57]. Couturier et al. [54] reviewed various conceptualizations of remission in adolescent anorexia nervosa and reached the conclusion that remission is best defined as the attainment of a certain weight and/or the attainment of normal EDE scores (within 1 or $2 \mathrm{SD}$ of the normal range, depending on the distribution). Bardone-Cone et al. [57] defined 
recovery as no longer meeting diagnostic criteria for anorexia nervosa, showing a BMI $\geq 18.5$, no binging or purging, and EDE scores within 1 SD of community norm for each subscale. All these definitions compare individuals' outcomes with a norm at a predefined assessment time. However, they do not consider changes resulting from treatment. As Frank et al. [53] stated, remission and recovery are an assessment of outcome at a single point and are not entirely dependent on treatment. However, response is a change due to treatment that requires baseline and posttreatment scores. In this sense, the first criterion of the concept of clinical significance (reliable change) assesses response to treatment. A clinically significant change requires both response to treatment as well as achieving a functional range at endpoint assessment. A clinical significant change may therefore be seen as remission, but considers response to treatment, too. Therefore, the criteria of clinical significance may be a more appropriate definition for evaluating treatment outcome.

\section{Future research}

In order to optimize treatment, future studies should explore the complex interplay of factors that may prevent patients with anorexia nervosa from non-responding to inpatient treatment. Then, treatment strategies for those should be developed. For those who improved during inpatient treatment, the challenge remains in maintaining therapy success following discharge. More attention should be paid to relapse prevention strategies, of which technology-based relapse prevention may be particularly useful [58,59]. Additional research should also address clarifying the impact of depressive symptoms or of depressive comorbidity on outcome for anorexia nervosa patients. Furthermore, future research should also investigate if patients' therapy motivation or stage of change as assessed by validated disorder-specific measures [60-62] are a predictor for a clinically significant change.

\section{Conclusions}

Inpatient treatment of anorexia nervosa is highly effective in restoring weight. A good proportion of patients show reliable changes in terms of eating disorder psychopathology, general psychopathology and depression. However, a significant proportion of non-responders remain. Supplementing group statistics with analyses of outcome on an individual level is suitable for obtaining a more precise picture of treatment outcome and is of immense practical relevance.

\section{Additional files}

Additional file 1: Pre-treatment scores of patients, community norms, Cronbach's Alpha and criterion C for each outcome measure.
Additional file 2: Classification of treatment outcome (EDI-2 subscales) based on the criteria of Jacobson and Truax [14].

\section{Abbreviations}

BMI: Body-mass-index; EDE: Eating disorder examination; ICD-10: International statistical classification of diseases and related health problems; EDI-2: Eating disorder inventory-2; BSI: Brief symptom inventory; GSI: Global severity index; BDI-2: Beck depression inventory-2; ES: Effect size; Mpre: Mean pre (at admission); Mpost: Mean post (at discharge); SDpre: Standard deviation pre (at admission); RCI: Reliable change index; SPSS: Statistical package for social sciences; G1: Group 1 (deteriorated/unchanged patients); G2: Group 2 (reliably improved patients); G3: Group 3 (clinically significantly improved patients).

\section{Competing interests}

The authors declare that they have no competing interests.

\section{Authors' contributions}

$\mathrm{SS}, \mathrm{NQ}, \mathrm{BL}, \mathrm{UC}$, UV have contributed to conception and design of the study. SS conducted the statistical analyses and wrote the first draft of the manuscript. NQ advised statistical analyses, contributed to interpretation of data and critically revised the manuscript. BL, UC and UV were involved in the interpretation of the results and in the critical appraisal of drafts. All authors read and approved the final manuscript.

\section{Acknowledgements}

The authors want to thank Raimund Schlemer for data entry and Dipl.-Psych. Kerstin Föll for her contributions to data management and analysis.

There was no funding for this study.

\section{Author details}

${ }^{1}$ Department of Psychiatry and Psychotherapy, University Hospital of Munich (LMU), Munich, Germany. ${ }^{2}$ Department of Psychosomatic Medicine and Psychotherapy, University Medical Center Hamburg-Eppendorf, Hamburg, Germany. ${ }^{3}$ Schoen Klinik Hamburg Eilbek, Hamburg, Germany. ${ }^{4}$ Schoen Klinik Roseneck, Prien, Germany. ${ }^{5}$ Paracelsus Medical University, Salzburg, Austria. ${ }^{6}$ Department of Psychiatry and Psychotherapy, University Hospital of Freiburg, Freiburg, Germany.

Received: 2 May 2014 Accepted: 29 August 2014

Published: 6 September 2014

\section{References}

1. Smink FR, van Hoeken D, Hoek HW: Epidemiology of eating disorders: incidence, prevalence and mortality rates. Curr Psychiatry Rep 2012, 14(4):406-414.

2. Arcelus J, Mitchell AJ, Wales J, Nielsen S: Mortality rates in patients with anorexia nervosa and other eating disorders: a meta-analysis of 36 studies. Arch Gen Psychiatry 2011, 68(7):724-731.

3. Löwe B, Zipfel S, Buchholz C, Dupont Y, Reas DL, Herzog W: Long-term outcome of anorexia nervosa in a prospective 21-year follow-up study. Psychol Med 2001, 31(5):881-890.

4. Zipfel S, Wild B, Gross G, Friederich H-C, Teufel M, Schellberg D, Giel KE, de Zwaan M, Dinkel A, Herpertz S, Burgmer M, Löwe B, Tagay S, von Wietersheim J, Zeeck A, Schade-Brittinger C, Schauenburg H, Herzog W, ANTOP study group: Focal psychodynamic therapy, cognitive behaviour therapy, and optimised treatment as usual in outpatients with anorexia nervosa (ANTOP study): randomised controlled trial. Lancet 2014, 383(9912):127-137.

5. Herpertz-Dahlmann B, Schwarte R, Krei M, Egberts K, Warnke A, Wewetzer C, Pfeiffer E, Fleischhaker C, Scherag A, Holtkamp K, Hagenah U, Bühren K, Konrad K, Schmidt U, Schade-Brittinger C, Timmesfeld N, Dempfle A: Daypatient treatment after short inpatient care versus continued inpatient treatment in adolescents with anorexia nervosa (ANDI): a multicentre, randomised, open-label, non-inferiority trial. Lancet 2014, 383(9924):1222-1229.

6. Schmidt U, Oldershaw A, Jichi F, Sternheim L, Startup H, Mclntosh V, Jordan J, Tchanturia K, Wolff G, Rooney M, Landau S, Treasure J: Out-patient psychological therapies for adults with anorexia nervosa: randomised controlled trial. Br J Psychiatry 2012, 201(5):392-399. 
7. APA: Practice Guideline for the Treatment of Patients with Eating Disorders, Volume 3rd. Washington (DC): American Psychiatric Association (APA); 2006.

8. NICE: National Collaborating Centre for Mental Health: Eating disorders: Core interventions in the treatment and management of anorexia nervosa, bulimia nervosa and related eating disorders. London: British Psychological Society, Royal college of Psychiatrists; 2004.

9. Herpertz S, Herpertz-Dahlmann B, Fichter M, Tuschen-Caffier B, Zeeck A: S3-Leitlinie Diagnostik und Behandlung der Essstörungen. Berlin: Springer; 2011.

10. Bowers WA, Ansher LS: The effectiveness of cognitive behavioral therapy on changing eating disorder symptoms and psychopathy of 32 anorexia nervosa patients at hospital discharge and one year follow-up. Ann Clin Psychiatry 2008, 20(2):79-86.

11. Morris J, Simpson AV, Voy SJ: Length of stay of inpatients with eating disorders. Clin Psychol Psychother 2013, (Epub ahead of print).

12. Collin P, Power K, Karatzias T, Grierson D, Yellowlees A: The effectiveness of and predictors of response to, inpatient treatment of anorexia nervosa. Eur Eat Disord Rev 2010, 18(6):464-474.

13. Fichter MM, Quadflieg N: Six-year course and outcome of anorexia nervosa. Int J Eat Disord 1999, 26(4):359-385.

14. Jacobson NS, Truax P: Clinical significance: a statistical approach to defining meaningful change in psychotherapy research. J Consult Clin Psychol 1991, 59(1):12-19.

15. Long CG, Fitzgerald KA, Hollin CR: Treatment of chronic anorexia nervosa: a 4-year follow-up of adult patients treated in an acute inpatient setting. Clin Psychol Psychother 2012, 19(1):1-13.

16. Rø $\varnothing$, Martinsen EW, Hoffart A, Rosenvinge JH: Short-term follow-up of adults with long standing anorexia nervosa or non-specified eating disorder after inpatient treatment. Eat Weight Disord 2004, 9(1):62-68.

17. Tagay S, Düllmann S, Schlegl S, Nater-Mewes R, Repic N, Hampke C, Brähler E, Gerlach G, Senf W: Effekte stationärer Psychotherapie auf Essstörungssymptomatik, gesundheitsbezogene Lebensqualität und personale Ressourcen bei Anorexia und Bulimia nervosa. Psychother Psychosom Med Psychol 2011, 61(7):319-327.

18. Zeeck A, Hartmann A, Wetzler-Burmeister E, Wirsching M: Zum Vergleich stationärer und tagesklinischer Behandlung der Anorexia Nervosa. Z Psychosom Med Psychother 2006, 52(2):190-203.

19. Goddard E, Hibbs R, Raenker S, Salerno L, Arcelus J, Boughton N, Connan F, Goss K, Laszlo B, Morgan J, Moore K, Robertson D, Saeidi S, SchreiberKounine C, Sharma S, Whitehead L, Schmidt U, Treasure J: A multi-centre cohort study of short term outcomes of hospital treatment for anorexia nervosa in the UK. BMC Psychiatry 2013, 13(1):287.

20. Jacobson NS, Follette WC, Revenstorf D: Psychotherapy outcome research: methods for reporting variability and evaluating clinical significance. Behav Ther 1984, 15(4):336-352.

21. Calugi S, Dalle Grave R, Marchesini G: Longstanding underweight eating disorder: associated features and treatment outcome. Psychother Res 2013, 23(3):315-323.

22. Fairburn CG, Cooper Z: The Eating Disorder Examination (12th ed.). In Binge eating: Nature, assessment and treatment. Edited by Fairburn CG, Wilson GT. New York: Guilford; 1993:317-360.

23. Garner D, Olmstead M, Polivy J: Development and validation of a multidimensional eating disorder inventory of anorexia nervosa and bulimia. Int J Eat Disord 1983, 2:14-34

24. Paul T, Thiel A: Eating Disorder Inventory - 2. Deutsche Version. Göttingen: Hogrefe; 2004

25. Derogatis LR: Brief Symptom Inventory (BSI): Administration, scoring, and procedures manual. NCS Pearson: Minneapolis; 1993.

26. Franke G: BSI. Brief Symptom Inventory von L. R. Derogatis (Kurzform der SCL-90-R) - Deutsche Version. Beltz Test: Göttingen; 2000.

27. Beck AT, Steer RA, Brown GK: Manual for the Beck Depression Inventory-II. San Antonio: Psychological Corporation; 1996.

28. Hautzinger M, Keller F, Kühner C: BDI-II. Beck-Depressions-Inventar. Revision. Volume 2. Frankfurt: Pearson Assessment; 2009.

29. Grawe K, Donati R, Bernauer F: Psychotherapie im Wandel: Von der Konfession zur Profession. Göttingen: Hogrefe; 1994.

30. Bauer S, Lambert MJ, Nielsen SL: Clinical significance methods: a comparison of statistical techniques. J Pers Assess 2004, 82(1):60-70.

31. Lambert MJ, Ogles BM: The Efficacy and Effectiveness of Psychotherapy. In Bergin and Garfield's Handbook of Psychotherapy and behavior change. Volume 5. Edited by Lambert MJ. New York: John Wiley \& Sons, Inc; 2004.
32. Hartmann A, Weber S, Herpertz S, Zeeck A: Psychological treatment for anorexia nervosa: a meta-analysis of standardized mean change. Psychother Psychosom 2011, 80(4):216-226.

33. Rø $\varnothing$, Martinsen EW, Hoffart A, Rosenvinge J: Two-year prospective study of personality disorders in adults with longstanding eating disorders. Int J Eat Disord 2005, 37(2):112-118.

34. Benninghoven $D$, Jürgens $E$, Mohr A, Heberlein I, Kunzendorf S, Jantschek G: Different changes of body-images in patients with anorexia or bulimia nervosa during inpatient psychosomatic treatment. Eur Eat Disord Rev 2006, 14(2):88-96.

35. Derogatis LR: SCL-90-R, administration, scoring \& procedures manual-I for the R(evised) version. Baltimore: John Hopkins University School of Medicine; 1977.

36. Zeeck A, Hartmann A, Buchholz C, Herzog T: Drop outs from in-patient treatment of anorexia nervosa. Acta Psychiatr Scand 2005, 111(1):29-37.

37. Bewell CV, Carter JC: Readiness to change mediates the impact of eating disorder symptomatology on treatment outcome in anorexia nervosa. Int J Eat Disord 2008, 41(4):368-371.

38. Wade TD, Frayne A, Edwards SA, Robertson T, Gilchrist P: Motivational change in an inpatient anorexia nervosa population and implications for treatment. Aust N Z J Psychiatry 2009, 43(3):235-243.

39. Miller WR, Rollnick S: Motivational interviewing: Preparing people for change (2nd ed.). New York, NY US: Guilford Press; 2002.

40. Macdonald P, Hibbs R, Corfield F, Treasure J: The use of motivational interviewing in eating disorders: a systematic review. Psychiatry Res 2012, 200(1):1-11.

41. Karlsson GP, Clinton D, Nevonen L: Prediction of weight increase in anorexia nervosa. Nord J Psychiatry 2013, 67(6):424-432.

42. Vansteelandt K, Pieters G, Vanderlinden J, Probst M: Body dissatisfaction moderates weight curves in the inpatient treatment of anorexia nervosa. Int J Eat Disord 2010, 43(8):694-700.

43. Fichter MM, Quadflieg N, Hedlund S: Twelve-year course and outcome predictors of anorexia nervosa. Int J Eat Disord 2006, 39(2):87-100.

44. Calugi S, El Ghoch M, Conti M, Dalle Grave R: Depression and treatment outcome in anorexia nervosa. Psychiatry Res 2014, 218(1/2):195-200.

45. First MB, Williams JBW, Spitzer RL, Gibbon M: Structured Clinical Interview for DSM-IV-TR Axis I Disorders, Clinical Trials Version (SCID-CT). New York: Biometrics Research, New York State Psychiatric Institute; 2007.

46. Huas C, Godart N, Foulon C, Pham-Scottez A, Divac S, Fedorowicz V, Peyracque E, Dardennes R, Falissard B, Rouillon F: Predictors of dropout from inpatient treatment for anorexia nervosa: data from a large French sample. Psychiatry Res 2011, 185(3):421-426.

47. Hiller W, Schindler A: Response und remission in der psychotherapieforschung. Psychother Psychosom Med Psychol 2011, 61(3-4):170-176.

48. Kessler R, Glasgow RE: A proposal to speed translation of healthcare research into practice: dramatic change is needed. Am J Prev Med 2011, 40(6):637-644.

49. Shadish WR, Navarro AM, Matt GE, Phillips G: The effects of psychological therapies under clinically representative conditions: a meta-analysis. Psychol Bull 2000, 126(4):512-529.

50. McConnaughy E, Prochaska J, Velicer W: Stages of change in psychotherapy: measurement and sample profiles. Psychother Theor Res Pract 1983, 20(3):368-375.

51. Mander J, Teufel M, Keifenheim K, Zipfel S, Giel KE: Stages of change, treatment outcome and therapeutic alliance in adult inpatients with chronic anorexia nervosa. BMC Psychiatry 2013, 13(1):111.

52. Ogles BM, Lunnen KM, Bonesteel K: Clinical significance: history, application, and current practice. Clin Psychol Rev 2001, 21(3):421-446.

53. Frank E, Prien RF, Jarrett RB, Keller MB, Kupfer DJ, Lavori PW, Rush AJ, Weissman MM: Conceptualization and rationale for consensus definitions of terms in major depressive disorder: remission, recovery, relapse, and recurrence. Arch Gen Psychiatry 1991, 48(9):851-855.

54. Couturier J, Lock J: What is remission in adolescent anorexia nervosa? a review of various conceptualizations and quantitative analysis. Int J Eat Disord 2006, 39(3):175-183.

55. Couturier J, Lock J: What is recovery in adolescent anorexia nervosa? Int J Eat Disord 2006, 39(7):550-555.

56. Williams SE, Watts TKO, Wade TD: A review of the definitions of outcome used in the treatment of bulimia nervosa. Clin Psychol Rev 2012, 32(4):292-300.

57. Bardone-Cone AM, Harney MB, Maldonado CR, Lawson MA, Robinson DP, Smith $R$, Tosh A: Defining recovery from an eating disorder: 
conceptualization, validation, and examination of psychosocial functioning and psychiatric comorbidity. Behav Res Ther 2010 48(3):194-202

58. Bauer S, Okon E, Meermann R, Kordy H: Technology-enhanced maintenance of treatment gains in eating disorders: efficacy of an intervention delivered via text messaging. J Consult Clin Psychol 2012, 80(4):700-706.

59. Fichter M, Quadflieg N, Nisslmuller K, Lindner S, Osen B, Huber T, WunschLeiteritz W: Does internet-based prevention reduce the risk of relapse for anorexia nervosa? Behav Res Ther 2012, 50:180-190.

60. Serpell L, Teasdale JD, Troop NA, Treasure J: The development of the P-CAN, a measure to operationalize the pros and cons of anorexia nervosa. Int J Eat Disord 2004, 36(4):416-433.

61. Rieger E, Touyz S: Development of an instrument to assess readiness to recover in anorexia nervosa. Int J Eat Disord 2000, 28(4):387-396.

62. Rieger E, Touyz S, Beumont JV: The anorexia nervosa stages of change questionnaire (ANSOCQ): information regarding its psychometric properties. Int J Eat Disord 2002, 32:24-38.

doi:10.1186/s12888-014-0258-z

Cite this article as: Schlegl et al:: Specialized inpatient treatment of adult anorexia nervosa: effectiveness and clinical significance of changes. BMC Psychiatry 2014 14:258

\section{Submit your next manuscript to BioMed Central and take full advantage of:}

- Convenient online submission

- Thorough peer review

- No space constraints or color figure charges

- Immediate publication on acceptance

- Inclusion in PubMed, CAS, Scopus and Google Scholar

- Research which is freely available for redistribution 